\title{
A strictly economic explanation of gender roles: the lasting legacy of the plough
}

\author{
Alessandro Cigno ${ }^{1}$ \\ Received: 23 April 2020 / Accepted: 30 December 2020 / Published online: 5 February 2021 \\ ( $)$ The Author(s) 2021; This article is published with open access
}

\begin{abstract}
We show that the descendants of ancient farmers may have an interest in marrying among themselves, and thus maintaining the gendered division of labour originally justified on comparative-advantage grounds by the advent of the plough, even after they emigrate to a modern industrial economy where individual productivity depends on education rather than physical characteristics. The result rests on the argument that, if efficiency requires the more productive spouse to specialize in raising income, and the less productive one in raising children, irrespective of gender, an efficient domestic equilibrium will be implemented by a costlessly enforceable pre-marital contract stipulating that the husband should do the former and the wife the latter. A contract may not be needed, however, if time spent with children gives direct utility, because an efficient equilibrium may then be characterized by little or no division of labour.
\end{abstract}

Keywords Plough $\cdot$ Comparative advantage $\cdot$ Gender $\cdot$ Matching $\cdot$ Hold-up problem $\cdot$ ConSiminskitract enforcement $\cdot$ Migration

JEL C78 $\cdot \mathrm{D} 02 \cdot \mathrm{J} 16 \cdot \mathrm{J} 61$

\section{Introduction}

Alesina, Giuliano and Nunn (2013) bring empirical evidence in support of the hypothesis advanced by Boserup (1970) that the gendered division of labour, whereby men work outside the home raising income, while women specialize in domestic, prevalently child-raising activities, draws its origins from the introduction of the plough some four thousand years ago. Unlike shifting cultivation, which is very labour intensive but requires no special physical characteristics, plough

Alessandro Cigno

alessandro.cigno@unifi.it

1 Department of Economics and Management, University of Florence, Florence, Italy 
cultivation is in fact less labour intensive but requires "upper body strength, grip strength, and bursts of power" which are more likely to be found in men than in women. That gives the former a comparative advantage over the latter in agricultural production. The first of the two articles cited reports that European and US residents descending from populations who used the plough in their countries of origin display still today, in their country of destination, less equal gender attitudes than the descendants of populations who did not have that experience. That is amazing. Why is the legacy of the plough still felt after countless other innovations have drastically reduced the importance of physical characteristics in the determination of individual productivity, and the share of the population employed in the agricultural sector? And why was this legacy not lost when migration offered the descendants of ancient plough users the opportunity to marry outside their ethnic group? The often heard argument that women are genetically programmed to enjoy raising children more than men do is irrelevant in the present context, because it should apply to everybody, not just to the descendants of ancient plough users. Another often heard argument is that men took advantage of the power achieved when physical strength mattered to indulge their taste for discriminating against women. The problem with this argument is that discrimination has an efficiency cost (Becker (1957)), and that the cost of discriminating against women rises as technological progress increases the importance of education vis-a-vis physical characteristics.

In the present paper we use a simple economic model of marriage and household decisions where men and women are matched by their potential incomes as singles, and then Nash-bargain the allocation of their joint time and money endowments. Parents have no gender preferences. We show that, so long as utility depends only on the agent's consumption of a private good, and on a domestically produced public good reflecting the quality (of life) of the couple's children, then, in equilibrium, the higher-wage spouse will specialize in income production, the lower-wage one will specialize in domestic activities, and the two will consume the same amount of the private good. There is a potential hold-up problem however. The lower paid spouse will not agree to give up paid work unless the equilibrium is enshrined in an enforceable pre-marital contract or, failing that, the better paid spouse compensates her or him at front (before the children are born, and resources expended on them). The latter may not be possible because the more productive spouse's initial endowment of the private good may not be large enough. The former may be prohibitively expensive if the enforcement can only be done by legal means. The problem does not arise in a primitive agrarian economy where the plough is not available, because efficiency does not require specialization. It may arise in one where the plough gives men a comparative advantage over women in agricultural production. In the traditional societies that we usually associate with primitive agrarian economies, however, a pre-marital contract is costlessly implemented, if it is in everybody's interest that it should, by the threat of extra-legal sanctions at the hands or with approval of the local community.

So long as education does not yield direct utility, children will not get one in a primitive economy where productivity is independent of education, but this may change with emigration to a modern industrial economy where education raises the probability of getting a high wage rate. We show that, in the destination country, the descendants of ancient farmers who never experienced the plough will give their 
daughters as much education as their sons. By contrast, under certain conditions, the descendants of ancient plough users have an interest in marrying among themselves (practicing homogamy) and investing in their sons, but not in their daughters' education. The story changes somewhat if individuals derive direct utility also from a luxury good like time spent with children, because an NB equilibrium may then involve little or no specialization, and there may thus be no need for advance compensation. As more and more individuals become rich enough to want these goods, fewer and fewer of them will then practice homogamy and specialize on gender lines.

\section{Basic assumptions}

As in much of the economics of the family literature, ${ }^{1}$ we assume that the agent derives utility from her or his own consumption of a private good ("money") and, if married, from a number of domestically produced, couple-specific public goods representing the quality (of life) of the couple's children. ${ }^{2}$ Later in the paper we shall allow for additional sources of utility. For simplicity, we further assume that, if individual $i$ marries, the couple have a daughter $D$ and a son $S .{ }^{3}$ Therefore, the decision to marry coincides with the decision to become a parent (we will later show that everybody marries).

Let $c_{i}$ denote $i$ 's consumption of the private good, and $g_{K}$ the quality of child $K$ 's life (a couple-specific public good), where $K=D, S$. To fix ideas and facilitate calculations, we take the utility function to be linear,

$$
U_{i}=c_{i}+g_{D}+g_{S}
$$

and $g_{K}$ to be a log-linear function of the amount of money $y_{K}$, and time ("attention") $a_{K}$, that the couple jointly spend on $K$,

$$
g_{K}=\ln y_{K}+\gamma \ln a_{K}, 0<\gamma<1 .
$$

Notice that not only maternal and paternal money contributions, but also maternal and paternal time contributions, are perfect substitutes in the domestic production of child quality. Notice also that parents do not harbour gender preferences. If daughter and son enter the picture symmetrically also in every other respect (as is very often the case in the economics of the family literature), there is then no need to keep their identities separate. We keep them separate because, in Section 4 below, we will find that gender may matter even if daughter and son are interchangeable where their parents' utility is concerned.

\footnotetext{
$\overline{1}$ See, among others, Becker (1981), Cigno (1991) and Folbre (1994).

2 The latter implies that parents are altruistic towards their children. Non-altruistic explanations of why couples have children and expend resources on them are offered by, among others, Cigno (1993) and Botticini \& Siow (2003).

3 Allowing for the number of children to be a random variable with probability distribution conditional on certain parental actions, and assuming that a child will be born male or female with equal probability, would complicate the analysis without altering our results in any substantial way.
} 
Parents and their children play a two-stage game. At stage 1, the couple allocate their children a certain amount of money (optimally allocated between cash-in-hand and educational expenditure), and a certain amount of attention. At this stage, their children's stage- 2 wage rates or productivities may be uncertain. At stage 2, when these wage rates or productivities are revealed, the children decide whether and whom to marry. The model is solved by backward induction.

\section{Modern economies}

We start by considering a modern industrial economy where the wage rate depends only on education and chance. Specifically, we assume that individual $i$ 's wage rate is $w_{i}=w^{H}$ with probability $\pi\left(z_{i}\right)$, and $w_{i}=w^{L}<w^{H}$ with probability $1-\pi\left(z_{i}\right)$, where $z_{i}$ denotes $i$ 's education. ${ }^{4}$ The function $\pi($.$) is increasing and concave, with \pi(0)=0$.

\subsection{Stage 2}

At this stage, $i$ is endowed with one unit of time and $b_{i}$ units of money, and commands a known wage rate $w_{i}$. If $i$ stays single, her or his utility is measured by her or his consumption, equal to to her or his income,

$$
R_{i}:=c_{i}=b_{i}+w_{i} .
$$

If $i$ marries, the couple Nash-bargain the allocation of their joint time and money endowments, and the distribution of their joint income. Player $i$ 's reservation utility is equal to her or his utility as a single, $R_{i}$. We plausibly assume that men and women are matched by their reservation utilities, and that the distribution of these utilities is the same for men and women. If several individuals of each gender have the same reservation utility, they are sorted into couples in such a way, that $i$ 's utility is maximized given $R_{i}$.

Take the couple formed by a particular woman, $f$, and a particular man, $m$. Having assumed that

$$
R_{f}=R_{m}=R
$$

it follows that

$$
w_{m}-w_{f}=b_{f}-b_{m} .
$$

The Nash-bargaining (NB) equilibrium maximizes

$$
N=\left(U_{f}-R\right)\left(U_{m}-R\right),
$$

subject to $f$ 's and $m$ 's budget constraints,

$$
c_{f}=b_{f}+(1-2 \delta a) w_{f}-y+T
$$

and

$$
c_{m}=b_{m}+[1-2(1-\delta) a] w_{m}-y-T,
$$

\footnotetext{
${ }^{4}$ If education is compulsory up to a certain level, $z_{i}$ is measured from that minimum.
} 
where $0 \leq \delta \leq 1$ denotes $f$ 's share of $a$, and $T$ is defined as a transfer (positive, negative or zero) from $m$ to $f$. Each parent is conventionally assigned the monetary cost of one child, $y$, but the amount effectively contributed will depend on the sign and size of $T$.

Given that $D$ and $S$ enter the optimization symmetrically, in equilibrium, $D$ and $S$ are treated the same,

$$
y_{K}=y, a_{k}=a \text { and } g_{K}=g .
$$

Given also that $a_{f}$ and $a_{m}$ are perfect substitutes in the production of $g$, the choice of $\delta$ will be either at a corner ( 1 or 0$)$, or indeterminate. ${ }^{5}$ For any given $\delta$, the first-order conditions on the choice of $a, y$ and $T$ are, respectively,

$$
\begin{gathered}
\left(-2 \delta w_{f}+2 \frac{\gamma}{a}\right)\left(U_{m}-R\right)+\left[-2(1-\delta) w_{m}+2 \frac{\gamma}{a}\right]\left(U_{f}-R\right)=0, \\
\left(-1+\frac{2}{y}\right)\left(U_{m}-R\right)+\left(-1+\frac{2}{y}\right)\left(U_{f}-R\right)=0
\end{gathered}
$$

and

$$
\left(U_{m}-R\right)-\left(U_{f}-R\right)=0
$$

In equilibrium,

$$
U_{f}=U_{m}=U
$$

and

$$
y=2 \text {. }
$$

The values of the other variables depend on the parents' relative wage rates.

For $w_{f}=w^{L}, w_{m}=w^{H}$, the couple choose

$$
\delta=1, a=\frac{2 \gamma}{w^{L}}, T=2 \gamma .
$$

In this case, $f$ allocates all her time to the production of child quality, and $m$ to the production of income. Consequently, he compensates her for forgone earnings. Their common utility level is

$$
U^{*}(R):=R-2(1+\gamma)+2\left(\ln 2+\gamma \ln \frac{2 \gamma}{w^{L}}\right) .
$$

In the opposite case, where $w_{f}=w^{H}, w_{m}=w^{L}$, the couple choose

$$
\delta=0, a=\frac{2 \gamma}{w^{L}}, T=-2 \gamma .
$$

The only difference between this and the previous case is in the sign of $T$. As $m$

\footnotetext{
${ }^{5}$ If the mother and the father's time contributions substituted at a diminishing marginal rate, the solution could be interior, and the specialization less than full, but this would make no difference of substance to the results.
} 
now does all the child related work, and $f$ all the income related work, it is now her who compensates him for loss of earnings. ${ }^{6}$ But the common utility level is still $U^{*}(R)$.

For $w_{f}=w_{m}=w$, the couple are indifferent between splitting the two types of work equally between them, or spinning a coin. Assuming the former,

$$
\delta=\frac{1}{2}, a=\frac{2 \gamma}{w}, T=0
$$

There is no compensation. If $w=w^{L}$, the couple's common utility level is again $U^{*}(R)$. But, if $w=w^{H}$, the common utility level is only

$$
U^{\circ}(R):=R-2(1+\gamma)+2\left(\ln 2+\gamma \ln \frac{2 \gamma}{w^{H}}\right)<U^{*}(R)
$$

because the children's opportunity-cost is in that case higher than in the other.

Therefore, a marriage between two high-wage persons is inefficient. In an efficient matching, a high-wage person is always married to a low-wage person, because the latter is indifferent between marrying a high-wage or a low-wage person with the same $R$, but the former is better-off marrying a low-wage person with the same $R$. Realistically assuming that children are born at (or close to) the start of stage 2 , but wages are paid at the end (or at any rate in the course) of it, however, an NB equilibrium where the spouses have different wage rates may not be implementable. Given that once the children are born they cannot be sent back, and making the usual assumption that a complete, legally enforceable pre-marital contract is out of the question because the transactions cost is prohibitively high for ordinary folk, the lowwage spouse will in fact demand to be paid at front. But, this payment will not be forthcoming if the high-wage spouse's money endowment is lower than the compensation due, and credit is rationed. If that is the case, there is a hold-up problem. The efficient equilibrium cannot be implemented. For $w_{i}=w^{L}, i$ will then marry a high-wage member of the opposite sex with money endowment greater than $2 \gamma$ or, if there are not enough of these, another low-wage person. In either case, $i$ will get the utility level $U^{*}\left(R_{i}\right)$. By contrast, if $w_{i}=w^{H}$, and $b_{i}$ is less than $2 \gamma, i$ will have no choice but to marry another high-wage person, and get the utility level $U^{\circ}\left(R_{i}\right)$, which is not as good as $U^{*}\left(R_{i}\right)$, but still better than remaining single and getting only $R_{i}$. Therefore, everybody marries.

It may be argued that, in a developed society, there are legal instruments, other than a court-enforceable contract, which may obviate the emergence of a hold-up problem. Cigno (2012) shows that marriage may substitute for a fully contingent premarital contract if divorce is sufficiently inexpensive, and divorce courts can be relied upon to award compensation to the party who sacrificed her or his career prospects in order to specialize in domestic activities, because the party in question can then

\footnotetext{
6 This result rests on our assumption that the wage rate depends only on education and chance. Were we to allow for the possibility that the wage rate increases with the amount of time worked, that would make no difference to the results so long as mother and father were perfect substitutes in the production of child quality. If the father cannot substitute for the mother at least in the early part of a child's life as in Cigno (1993), however, it will be efficient for the father to specialize in market work even if his wage rate is initially no higher than the mother's. Siminski \& Yetsenga (2020) indeed find that the mother's productivity must be much larger than the father's for her to specialize in market, and him in domestic activities.
} 
credibly threaten divorce if the other party does not deliver the compensation voluntarily. But this is unavoidably uncertain, because there are verifiability problems, and also because of court discretionality. Therefore, the availability of lowcost divorce, and the possibility that the compensation for the spouse who specialized in domestic work would be mandated by a divorce court, reduces but does not eliminate the probability of a hold-up problem.

\subsection{Stage 1}

At this stage, $i$ 's parents play the same kind of game that $i$ and $i$ 'spouse will play at the next one. Parents thus Nash-bargain over the allocation of their joint time and money endowments, and over the destination of their joint income. Omitting the identifying subscript because $i$ and $i$ 's brother or sister receive the same treatment, each child is then assigned the equilibrium amount of money $y=2$, allocated between cash in hand, $b$, and educational expenditure, $z$, so as to maximize the child's expected utility,

$$
E U^{*}=E R+C
$$

where

$$
C=2\left(\ln 2+\gamma \ln \frac{2 \gamma}{w^{L}}\right)-2(1+\gamma),
$$

subject to

$$
b+z=2,
$$

and to the further restriction that, if the realized value of $w$ is $w^{H}$, the child must be able to pay her or his future spouse the equilibrium amount of compensation $T=2 \gamma$ at the start of stage 2 ,

$$
b \geq 2 \gamma
$$

This problem has either an interior solution at $\left(b=2-z^{*}, z=z^{*}\right)$, where $z^{*}$ solves

$$
\left(w^{H}-w^{L}\right) \pi^{\prime}(z)=1,
$$

or a corner solution at $(b=2 \gamma, z=2(1-\gamma))$.

\section{From primitive to modern economies}

A primitive agrarian economy differs from a modern industrial one in that a person's wage rate is independent of education (we continue to talk of wage rate even though there may not be a labour market and, if that is the case, we should talk of physical productivity). Parents may then give a child money, but never an education. ${ }^{7}$ All we said in the last section regarding the need to guarantee the actual delivery of $T=2 \gamma$

\footnotetext{
7 That is obviously a simplification. In reality, a small minority of prospective priests, scribes and astrologers will receive an education of sorts.
} 
for an NB equilibrium with domestic division of labour to be implementable, still applies. Let there be two such economies, A and B. For geographical reasons, the plough is available in country $\mathrm{B}$, but not in country $\mathrm{A} .{ }^{8}$ In the latter, the wage rate is equal to $w^{L}$ for everybody, and consequently $\delta=\frac{1}{2}$ for all couples. There is then no question of a spouse having to compensate the other, and no risk of a hold-up problem. In country B, by contrast, the woman's wage rate is $w^{L}$, but the man's is $w^{H}$ thanks to the plough technology. Therefore, $\delta=1$. Is there then a potential hold-up problem as in a modern industrial economy?

In the traditional societies that we associate with primitive agrarian economies, a contract may be enforced not only by a law court, but also, if it is in everybody's interest that the contract should be honoured, by the threat of severe extra-legal sanctions (ranging from ostracism to physical punishment, or even murder) at the hands or with the approval of the entire community. ${ }^{9}$ In equilibrium, this form of enforcement costs nothing, because the threat does not need to be carried out. In country B, this applies to pre-marital contracts, because every couple has a daughter and a son. At stage 1 of the game, it is thus in every couple's interest that their son should be able to follow his comparative advantage in agricultural production, but their son-in-law should not be allowed to turn his comparative advantage into a bargaining advantage at their daughter's expense. Generation after generation, therefore, all country B couples comply with a simple contract, the same for all of them, specifying that the wife must spend all her time attending to the children, that the husband must spend all his producing income, and that the spouses will consume the same amount of the private good. No such contract is needed in country A, where the NB equilibrium does not involve specialization.

Now suppose that a large number of couples emigrate from A and B to a modern economy. Observing that, in their new country, educated workers command, on average, a higher wage rate than uneducated ones, these immigrants will consider the merits of investing in their children's education. If a couple originate from country A, they have no reason to treat their daughter differently from their son. They will then give each of their children $\left(b=2-z^{*}, z=z^{*}\right)$ if (17) is not binding, $(b=2 \gamma, z=2(1-\gamma))$ if it is. What if the immigrant couple originate from country B? Suppose that they can rely, in their new country, on the same extra-legal methods that are used in their country of origin to costlessly enforce a pre-marital contract envisaging domestic specialization along gender lines. That introduces an asymmetry in the way the couple treat their children. Their son will in fact receive $\left(b=2-z^{*}, z=z^{*}\right)$, but their daughter, will get $(b=2, z=0)$ because it is certain that she will do no paid work. Further supposing that $i$ can invoke the enforcement methods in question only if, not only $i^{\prime}$ s own parents, but also her or his spouse's are country B immigrants, it is then in $i$ 's interest to find a spouse with the same

\footnotetext{
${ }^{8}$ Using a wealth of archaeological and linguistic evidence, Diamond (2005) argues that the reason why agriculture and certain agricultural technologies developed in certain parts of the world rather than others, and spread in certain directions rather than others, is due to geographical factors.

9 For a game-theoretical analysis of these enforcement mechanisms, see Axelrod (1984), Fudenberg \& Maskin (1986), Kandori (1992), Cigno, Komura and Luporini (2017) and Cigno et al. (2020). Akerlof \& Kranton (2000) effectively argue that no enforcement is required if individuals derive disutility from deviating from group behaviour. For an economic history approach, see Ostrom (1990) and Greif (2006). For a Darwinian approach, see Richerson \& Boyd (2006).
} 
ascendancy. The same will apply also to $i$ 's children, children's children, and so on. In their own and their children's interest, the descendants of ancient plough users will then marry among themselves.

Would an amended contract stipulating that the spouse with the higher wage rate must specialize in raising income, and the one with the lower wage rate in raising children, irrespective of gender, do just as well or even better in a modern industrial economy where individual productivity depends on education rather than gender? The answer is no because education is a risky investment. Given that, under the amended contract, all children of country B immigrants would receive $z^{*}$ units of education, a share $\left[1-\pi\left(z^{*}\right)\right]$ of these children would in fact end up specializing in domestic activities, and the money invested in their education would consequently be wasted. Besides, for $\pi\left(z^{*}\right)$ greater than 0.5 , at stage 2 of the game there would be more high-wage men (women) than low-wage women (men). Consequently, some high-wage men would have to marry high-wage women, and content themselves with the utility level $U^{\circ}(R)<U^{*}(R)$. Under the ancestral contract, by contrast, only the money spent educating $\left[1-\pi\left(z^{*}\right)\right]$ of the male half of the population (i.e., $\frac{1-\pi\left(z^{*}\right)}{2}$ of the total) is wasted, because the female half receives no education. Under this contract, therefore, every man (no matter whether high or low-wage) marries a lowwage woman, and every man or woman gets the utility level $U^{*}(R)$. Consequently, the allocation induced by the ancestral contract Pareto-dominates the one that would be induced by the amended contract, and the descendants of country B immigrants have no incentive to carry out the amendment.

\section{Extensions}

The model we have used so far assumes that people derive direct utility only from their own consumption and their children's quality, and that the latter depends only on the amount of money and parental attention received by each child. The money is optimally allocated between education and cash in hand, but education is only a means of increasing the child's expected wage rate. What happens if the parent's education increases the productivity of the attention he or she gives to her or his children, or directly raises the parent's own utility? And what if the time parents spend with their children also yields direct utility? We examine the different possibilities in turn. Throughout, we write $a_{i K}$ for the attention that parent $i$ gives child $K$ $=D, S$, and set $a_{i}=a_{i D}+a_{i S}$. Substituting $a_{f}$ for $\delta a$ and $a_{m}$ for $(1-\delta) a$, the budget constraints remain the same as in (7) $-(8)$.

\subsection{Education makes attention more productive}

Let us go back to stage 2 of the game. The utility function is still (1), but we now assume that $i$ 's education makes $i$ 's attention more productive in the domestic production of child quality. Instead of (2), we then write

$$
g_{K}=\ln y_{K}+\gamma \ln \left(z_{f} a_{f K}+z_{m} a_{m K}\right) .
$$

We can think of $z_{i} a_{i K}$ as $i$ 's attention measured in efficiency unities, and of $z_{i} w_{i}$ as the effective opportunity-cost of a unit of $i$ 's attention. As in Subsection 3.1, the time 
allocation is either indeterminate or at a corner. Now, however, indeterminacy arises not when the parents have the same wage rate, but when the effective opportunitycost of giving attention is the same for both parents, $z_{f} w_{f}=z_{m} w_{m}$. If that is the case, mother and father give the same amount of attention to their children, and consequently supply the same amount of time to the labour market. Otherwise, the parent with the lower opportunity-cost will specialize completely in raising children, and the other in raising income. Compared with the basic model, the only difference this extension makes is that, at stage 1 of the game, a girl may receive some education even if she is destined to specialize completely in domestic work at stage 2 , because the education she receives makes the attention that she will give to her children more productive. This weakens but does not overturn the argument according to which it is in the interest of country B immigrants, and of their descendants, to marry among themselves in order to preserve the enforceability of their ancestral contract.

\subsection{Education gives direct utility}

What happens if education yields direct utility? Realistically assuming that education for its own sake is a luxury good, the demand for it will be negligible among the poor, but not necessarily among the rest of the population. The utility function may now be written as

$$
U_{i}=c_{i}+\alpha_{i} \ln z_{i}+g_{D}+g_{S},
$$

where $\alpha_{i}$ is a parameter measuring $i$ 's taste for education. To capture the luxury good idea, we assume $\alpha_{i}=0$ for $c_{i} \leq \underline{c}$, and $\alpha_{i}=\alpha>0$ for $c_{i}>\underline{c}$, where $\underline{c}$ is the consumption level above which people do not regard themselves as poor. The other variables and parameters are defined as in sections 2 and 3. In particular, $g_{K}$ is still determined by the domestic production function (2). We concentrate on the case where $\alpha_{i}=\alpha$, because the one where $\alpha_{i}=0$ is the same as the one examined in Section 3.

The only difference this extension makes at stage 2 of the game is that $i$ 's reservation utility is now

$$
R_{i}:=c_{i}+\alpha_{i} \ln z_{i}=b_{i}+w_{i} .
$$

Given (4), this affects the stage-2 equilibrium only in that the equilibrium value of $U$ is now higher than in the basic model. The equilibrium values of the choice variables remain the same. It makes a difference, however, to the choice of $z_{i}$ at stage 1 of the game.

If $i$ 's parents are not, and do not descend from, country B immigrants, they do not differentiate between sons and daughters. They then give $i\left(b_{i}=2-\widehat{z}, z_{i}=\widehat{z}\right)$, where $\widehat{z}$ solves

$$
\left(w^{H}-w^{L}\right) \pi^{\prime}\left(z_{i}\right)=1-\frac{\alpha_{i}}{z_{i}}
$$

instead of (18), if (17) is not binding, $(b=2, z=0)$ if it is. ${ }^{10}$ If $i$ 's parents hail from country $\mathrm{B}$, by contrast, (18) does not apply so long as $i$ marries someone with the

${ }^{10}$ Clearly, therefore, $\widehat{z}$, is larger than $z^{*}$, but the probability that (17) will not be binding is smaller than it would be if education did not give utility. 
same ancestry. If $i$ is a boy, he will then get the education level $\widehat{z}$. If $i$ is a girl, however, she will only get $z_{i}=\alpha$. The implications of allowing education to yield direct utility are thus similar to those of assuming that education makes parental attention more productive. At sufficiently high consumption levels, girls receive an education, but still less than boys do, and the gendered division of labour is not at risk.

\subsection{Time with children gives direct utility}

The story changes somewhat if we allow the time that parents spend with their children to yield direct utility. Assuming that the time thus spent is a luxury good (like education for its own sake), we may now write the utility function as

$$
U_{i}=c_{i}+2 g+2 \beta \ln a_{i},
$$

where $\beta_{i}$ is a measure of $i$ 's taste for $a_{i}$, with $\beta_{i}=0$ for $c_{i} \leq \underline{c}$, and $\beta_{i}=\beta>0$ for $c_{i}>\underline{c}$. The domestic production function is (2) as in the basic model.

Given that the marginal utility of $a_{i}$ tends to infinity as $a_{i}$ approaches zero, there is now no possibility of a corner solution. A NB equilibrium then satisfies (11)-(12) and, in place of (10),

$$
\left(-2 w_{f}+\frac{2 \gamma}{a_{f}+a_{m}}+\frac{2 \beta}{a_{f}}\right)\left(U_{m}-R\right)+\frac{2 \gamma}{a_{f}+a_{m}}\left(U_{f}-R\right)=0
$$

and

$$
\left(-2 w_{m}+\frac{2 \gamma}{a_{f}+a_{m}}+\frac{2 \beta}{a_{m}}\right)\left(U_{f}-R\right)+\frac{2 \gamma}{a_{f}+a_{m}}\left(U_{m}-R\right)=0 .
$$

Taken together, these two conditions imply

$$
\beta \frac{a_{f}-a_{m}}{a_{f} a_{m}}=w_{m}-w_{f} .
$$

Given that neither $a_{f}$ nor $a_{m}$ can be zero, the spouses do not specialize completely. If they have the same wage rate, they spend the same amount of time with the children. If they have different wage rates, the better paid spouse spends less time with the children than the worse paid one (but still spends some). In the absence of an enforceable contract, the better paid spouse will then have to compensate the worse paid one at front, and it is is thus possible that (17) will not hold. But the probability of this happening is lower than in the basic model (and in the extended versions examined in the last two subsections), because there is now less specialization, and the compensation due to the worse paid spouse is consequently smaller than in that model. Some individuals may then have no use for a contract. Even if they descend from country B immigrants, these individuals have thus no incentive to practice homogamy, and no reason to leave their daughters without an education.

\section{Conclusion}

In sections 2 and 3, we used a bare-bones model where people derive direct utility only from their own consumption, and from their children's quality, to demonstrate 
that, under certain conditions, the descendants of ancient plough users have an interest in marrying among themselves, and practicing the gendered division of labour, even if they move to a modern industrial economy where wage rates reflect education rather than gender. We demonstrated this without assuming that parents prefer sons to daughters, or that men somehow turned their initial comparative advantage into a permanent bargaining advantage. We did not make either of those assumptions not because they are false, but because they are neither necessary nor sufficient for our purposes. These predictions are consistent with the evidence reported in Alesina et al. (2013), that European and US residents descending from populations who used the plough in their countries of origin display, still today, less equal gender attitudes than the descendants of populations who did not have that experience (and that a similar difference emerges from a comparison of those who descend from ancient plough users on both the father and the mother's side, with those who do so only on one parent's side).

We then examined the possibility that education yields directly utility or enhances the productivity of the time parents spend with their children. As an alternative, we also considered the possibility that spending time with one's children gives direct utility. The first two extensions make no difference of substance to our results. They only allow for the possibility that girls will receive some education even if they are destined to specialize in domestic activities. The third extension, by contrast, makes an important difference. Assuming that time with children is a luxury good, the model does in fact predict that complete specialization may not be efficient. As more and more people rise above poverty as a result of economic progress, a larger and larger share of the descendants of ancient plough users may then be expected to lose interest in marrying among themselves, and specializing along gender lines. The evidence reported by Alesina et al. (2013) suggests, however, that there is still some way to go before the ancestral contract loses its purpose.

Acknowledgements Valuable comments by Dilip Mookherjee, Larry Samuelson and two anonymous referees are gratefully acknowledged. Editorial guidance by Shoshana Grossbard is also appreciated. Remaining errors or infelicites are the author's responsibility.

Funding Open Access funding provided by Università degli Studi di Firenze.

\section{Compliance with ethical standards}

Conflict of interest The author declares no conflict of interest.

Publisher's note Springer Nature remains neutral with regard to jurisdictional claims in published maps and institutional affiliations.

Open Access This article is licensed under a Creative Commons Attribution 4.0 International License, which permits use, sharing, adaptation, distribution and reproduction in any medium or format, as long as you give appropriate credit to the original author(s) and the source, provide a link to the Creative Commons license, and indicate if changes were made. The images or other third party material in this article are included in the article's Creative Commons license, unless indicated otherwise in a credit line to the material. If material is not included in the article's Creative Commons license and your intended use is not permitted by statutory regulation or exceeds the permitted use, you will need to obtain permission directly from the copyright holder. To view a copy of this license, visit http://creativecommons.org/licenses/by/4.0/. 


\section{References}

Akerlof, G., \& Kranton, R. E. (2000). Economics and identity. Quarterly Journal of Economics, 115, $715-753$.

Alesina, A., Giuliano, P., \& Nunn, N. (2013). On the origins of gender roles. Quarterly Journal of Economics, 128, 469-530.

Axelrod, R. (1984). The Evolution of Cooperation. New York: Basic Books.

Becker, G. S. (1957). The Economics of Discrimination. Chicago: The University of Chicago Press.

Becker, G. S. (1981). A Treatise on the Family. Cambridge (Mass.): Harvard University Press.

Boserup, E. (1970). Woman's Role in Economic Development. London: George Allen and Unwin.

Botticini, M., \& Siow, A. (2003). Why dowries? American Economic Review, 93, 1385-1398.

Cigno, A. (1991). Economics of the Family. New York and Oxford: Oxford University Press and Clarendon Press.

Cigno, A. (1993). Intergenerational transfers without altruism: family, market and state. European Journal of Political Economy, 9, 505-518.

Cigno, A. (2012). Marriage as a commitment device. Review of Economics of the Household, 10, $193-213$.

Cigno, A., Gioffré, A., \& Luporini, A. (2020). Evolution of individual preferences and persistence of family rules, Review of Economics of the Household, https://doi.org/10.1007/S11150-020-09499-7.

Cigno, A., Komura, M., \& Luporini, A. (2017). Self-enforcing family rules,marriage and the (non)neutrality of public intervention. Journal of Population Economics, 30, 805-834.

Diamond, J. (2005). Guns, Germs, and Steel: The Fates of Human Societies. New York: W. W. Norton.

Folbre, N. (1994). Children as public goods. American Economic Review, 84, 86-90.

Fudenberg, D., \& Maskin, E. (1986). The folk theorem inrepeated games with discounting or with incomplete information. Econometrica, 54, 533-554.

Greif, A. (2006). Institutions and the Path to the Modern Economy: Lessons from Medieval Trade. Cambridge: Cambridge University Press.

Kandori, M. (1992). Social norms and community enforcement. Review of Economic Studies, 59, 63-80.

Ostrom, E. (1990). Governing the Commons: The Evolution of Institutions for Collective Action. Cambridge: Cambridge University Press.

Richerson, P. J., \& Boyd, R. (2006). Not By Genes Alone. How Culture Transformed Human Evolution. Chicago: The University of Chicago Press.

Siminski, P., \& Yetsenga, R. (2020). Rethinking specialization and the sexual division of labour in the 21st century, IZA Institute of Labor Economics DP No. 12977. 